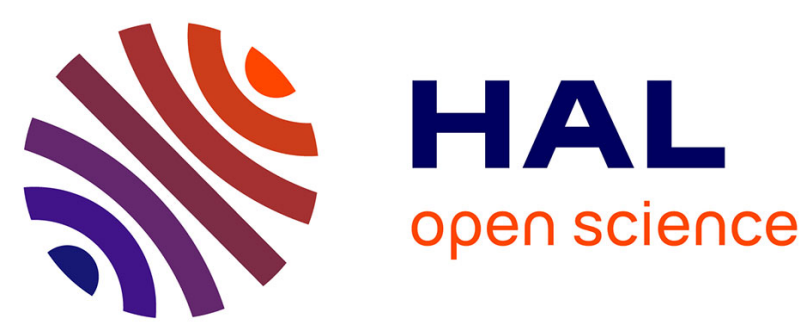

\title{
DETERMINATION OF MACROSCOPIC QUANTITIES FOR A TOWNSEND DISCHARGE IN HELIUM BY BOTH BOLTZMANN EQUATION AND MONTE CARLO METHODS
}

P. Segur, S. Pareathumby, Mohammed Yousfi, E. Marode

\section{To cite this version:}

P. Segur, S. Pareathumby, Mohammed Yousfi, E. Marode. DETERMINATION OF MACROSCOPIC QUANTITIES FOR A TOWNSEND DISCHARGE IN HELIUM BY BOTH BOLTZMANN EQUATION AND MONTE CARLO METHODS. Journal de Physique Colloques, 1979, 40 (C7), pp.C7-539C7-540. 10.1051/jphyscol:19797261 . jpa-00219247

HAL Id: jpa-00219247 https://hal.science/jpa-00219247

Submitted on 1 Jan 1979

HAL is a multi-disciplinary open access archive for the deposit and dissemination of scientific research documents, whether they are published or not. The documents may come from teaching and research institutions in France or abroad, or from public or private research centers.
L'archive ouverte pluridisciplinaire HAL, est destinée au dépôt et à la diffusion de documents scientifiques de niveau recherche, publiés ou non, émanant des établissements d'enseignement et de recherche français ou étrangers, des laboratoires publics ou privés. 
DETERMINATION OF MACROSCOPIC QUANTITIES FOR A TOWNSEND DISCHARGE IN HELIUM BY BOTH BOL TZMANN EQUATION AND. MONTE CARLO METHODS

\author{
P. Segur, S. Pareathumby, M. Yousfi and E. Marode*. \\ Laboratoire associé au C.N.R.S. N²77, Centre de Physique Atomique, 118, route de Narbonne, \\ * 31077 Toulouse Cedex. \\ * Laboratoire de Physique des déchaxges, Ecole Supérieure d'Electricité Plateau du Moulon, 91190 \\ Gif-sur-Yvette.
}

We compare the results obtained in the study of a weakly ionized gas for a Townsend dis charge which is developped in a steady uniform field. This study has been carried out in two laboratories : firstly at the Centre de Physique Atomique de Toulouse using Boltzmann equation (1) and secondly in Paris (Ecole Supérieure d'Electricité) by Monte Carlo simulation.

A lot of papers has been devoted to the microscopic study of weakly ionized gases in steady uniform fields. However, most of them deal with homogeneous states, which are attained far from the walls i.e. when the electrons are in equilibrium with the electric field. In many cases too, these studies deal with low values of the ratio electric field upon pressure $(E / P)$; we then have a great number of collisions, and the mean free paths are much smaller than the gap length. For high values of $E / P$, when the mean free paths are almost as great as the gap length, the methods of resolution of the Boltzmann equation normally used are no more valid. For such a case we developped a new technique based on the collision probability method well known in neutron physics. The method consists in a splitting of the phase space in spherical shells. The distribution function is assumed constant in each shell. This generates a linear system of equations in which the elements $P_{i, j}$ of the principal matrix can be considered as the collision probability that an electron, initiated in shell $i$, undergoes collision in shell $j$. If we assume the electron-atom collisions to be isotropic, the resolution of the linear system of equations gives us the isotropic part $\phi$ of the electron distribution function. A good number of the macroscopic quantities ruling the discharge can then be obtained from $\varnothing$ only (Electron density $n_{e}$, mean energy Em, excitation rates $\mathcal{D}_{\mathbf{k}}$ etc...). The other quantities (current $\mathrm{J}$, drift velocity $\mathrm{V}_{\mathrm{d}} \ldots$ ) are derived from a simple quadrature of the initial Boltzmann equation.

Contrary to the Boltzmann equation approach, the same Monte Carlo method can be used for both low and high values of $E / P$. The program we have developped is thus valid in the two cases. The only difficulty may eventually come from the computing time which may be prohibitive in the low $\mathrm{E} / \mathrm{P}$ case due to the great number of collisions involved.

To compare the two methods we choose a Townsend discharge between plane parallel plates in helium. The voltage applied is 150 volts corresponding to $E / P$ and $P . D$. values ( $D$ is the gap length) of $100 \mathrm{~V} . \mathrm{cm}^{-1}$. Torr ${ }^{-1}$ and 1 Torr.cm. respectively. We take a constant electron velocity function at the cathode of maximum energy $5 \mathrm{eV}$ and we assume the anode to be perfectly absorbing. In figure 1 we give the electron energy dis tribution function obtained by the two methods for the same position in the inter electrode space. The functions show similar behaviours in both cases. Fig. 2 shows the variation of the mean energy Em with the distance. The results are in very good agreement for the two methods. The energy first increases sharply from the cathode, then oscillates around a mean value. Finally Em grows in the proximity of the anode. This is in accordance with the continuity equation. The electron density varies inversely as $\mathrm{V}_{d}$ or $\mathrm{Em}$. Towards the anode there is a drop in density due to absorption, and thus an increase in the energy.

The $n_{e}(x)$ curve is displayed in fig. 3. The 
density decreases near the cathode since there is no ionization, then when the electrons gain enough energy to ionize there is an increase of the density. Finally $\mathrm{n}_{\mathrm{e}}$ decreases towards the anode due to $\mathrm{ab}-$ sorption. The densities obtained by Monte Carlo are somewhat lower near the anode.

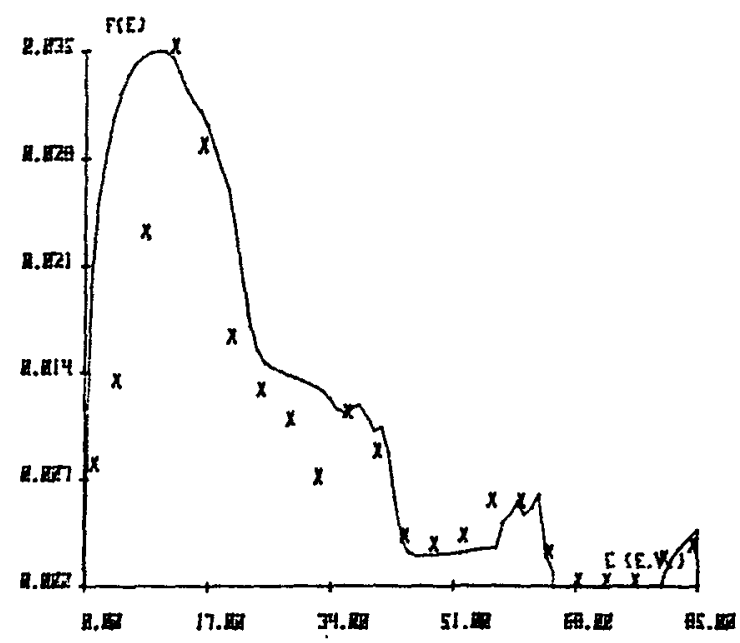

Fig. 1 - Electron energy distribution function.

- Boltzmann equation. $x$ Monte Caxlo method.

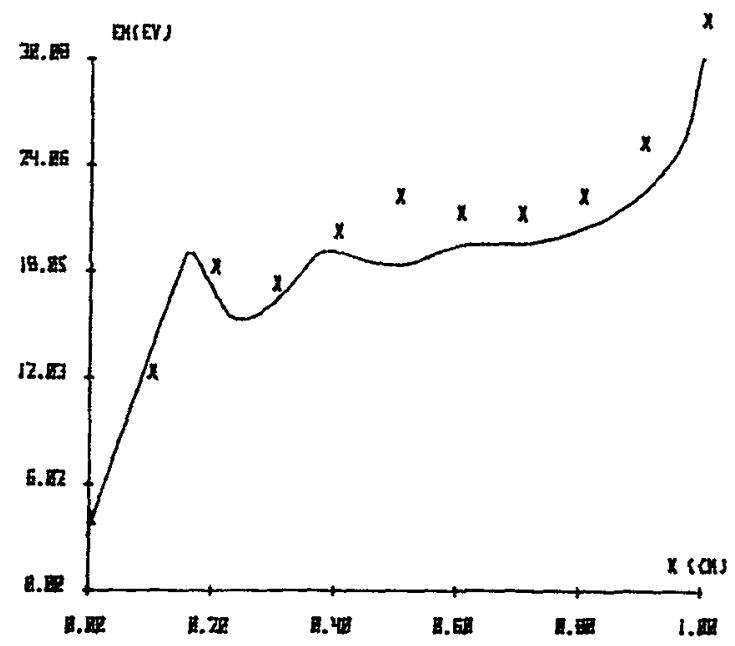

Fig. 2 - Mean energy.

- Boltzmann equation, $x$ Monte Carlo method.

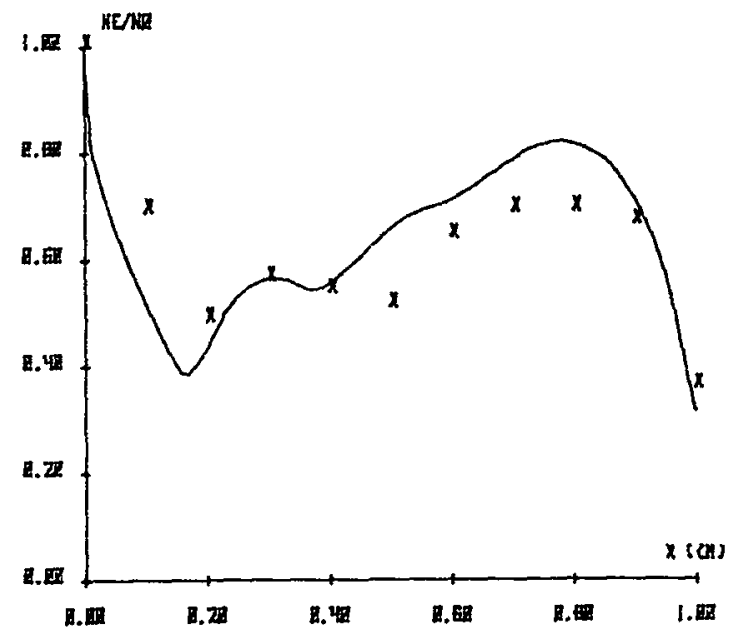

Fig. 3 - Electron density.

- Boltzmann equation, $x$ Monte Carlo method The variation of $\mathrm{J} / \mathrm{J}$ is shown in fig. 4 .

Here too the discrepancies between the two amplification factors are very weak.

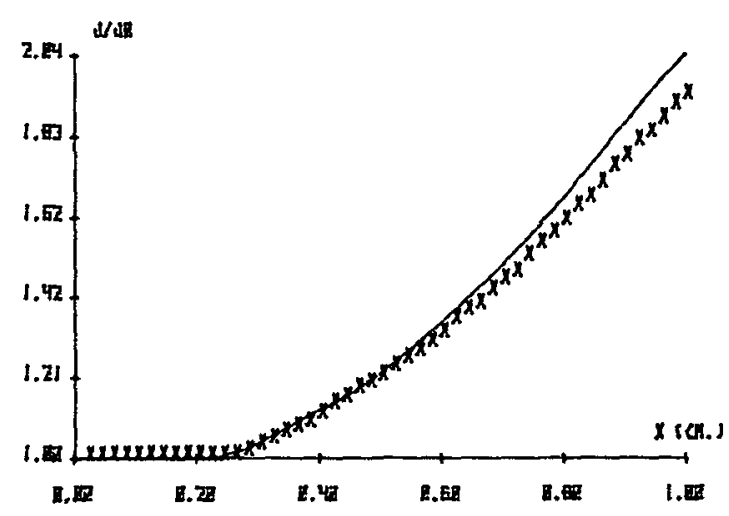

Fig. 4 - Amplification factor.

- Boltzmann equation, $x$ Monte Carlo method

The work exposed here is the first step in a British-French collaboration on the behaviour of electronegative discharges in the neighbourhood of the walls. In the next step we interd to inject our results for heterogeneous situations in macroscopic equations used by the British team.

1 - Pareathumby S. : Thèse $3^{\circ}$ cycle, $\mathrm{n}^{\circ} 2179$, Toulouse (1978). 